\title{
RELIGIÃO E POLÍTICA: ESTUDO SOBRE PARTIDOS “CRISTÃOS” NO CONTEXTO PAULISTANO DE 2020
}

\author{
Moisés Stefano Barel*
}

RESUMO

$\mathrm{O}$ artigo visa estudar o posicionamento estatutário de dois partidos políticos brasileiros que apresentam vínculos com o Cristianismo enquanto doutrina de fé e trazem este termo, ou derivações dele, incluídas em suas respectivas nomenclaturas registradas no Tribunal Superior Eleitoral (TSE), e analisar o desempenho eleitoral de cada uma dessas siglas na eleição parlamentar de 2020, com ênfase na disputa por cadeiras na Câmara dos Vereadores de São Paulo. Para realização do trabalho, foram usadas como técnicas de pesquisa revisão de bibliográfica e pesquisas virtuais, com o intuito de identificar se os partidos estudados conquistaram representatividade no legislativo municipal.

Palavras-chave: Eleição; Política; Legislativo; Partidos; Cristianismo.

\section{INTRODUCÃO}

A partir da redemocratização brasileira após 21 anos de Ditadura Militar (1964-1985) ampliou-se o espectro ideológico da representação político-partidária vivenciada no país, com siglas das mais diversas orientações representativas, seja no âmbito do tradicional dualismo de direita-esquerda, ou agremiações com linha discursiva mais segmentada em torno de agendas público-sociais como meio ambiente, defesa do trabalho e dos trabalhadores, representatividade da mulher, da família e da religiosidade, especialmente, o cristianismo, por conta de todo o seu enraizamento cultural no Brasil. Atualmente, existem 33 siglas eleitorais registradas no Tribunal Superior Eleitoral

* Doutorando em Comunicação Social pela Universidade Metodista de São Paulo. Mestre em Comunicação Social pela mesma instituição. Jornalista. E-mail: moisesbarel@yahoo.com.br. Bolsista através da Coordenação de Aperfeiçoamento de Pessoal de Nível Superior (Capes). Orientador: Prof. Dr. Luiz Alberto B. de Farias. 
(TSE), sendo as mais antigas registradas em 1981 (MDB, PTB e PDT) e a mais recente formalizada em 2019 (Unidade Popular).

É justamente neste período de reabertura política, em meados da década de 1980, que surgem os dois, dos quatro partidos que serão estudados neste artigo, por se apresentarem como possuidores de matrizes cristãs. O Partido Social Cristão (PSC), cujo número eleitoral é 20, foi criado em 15 de maio de $1985^{2}$. O Republicanos ${ }^{3}$, embora não faça menção explícita ao Cristianismo em seu nome, possui proximidade ideológica com a Igreja Universal do Reino de Deus, e já chegou a ser apontado pela imprensa como "ligado" à denominação religiosa ${ }^{4}$, embora estatutariamente, isto não se apresente. É representado pelo número 10 .

Através de pesquisas bibliográficas (Stumpf, 2005), pesquisas virtuais (Yamaoka, 2005) nos portais dos partidos estudados e na página do Tribunal Superior Eleitoral (TSE) e análises documentais (Moreira, 2005), ou seja, consultas aos estatutos partidários, pretendemos analisar posicionamentos ideológicos, hibridismos político-religiosos e resultados obtidos na eleição 2020, especificamente, no pleito para o cargo de vereador na cidade de São Paulo. Ao final, pretendemos tecer considerações sobre a presença das agremiações estudadas no legislativo paulistano, e também sobre os resultados eleitorais por elas obtidos.

\section{Hibridismos político-religiosos}

Sobre o ingresso de pessoas que professam a fé cristã na política, em especial lideranças evangélicas ou pessoas por elas apoiadas, Ricardo Mariano (2011), destaca que tais indivíduos perceberam a necessidade de ampliar a visibilidade pública de suas crenças e os interesses corporativos defendidos

MDB é o Movimento Democrático Brasileiro, anteriormente chamado de PMDB. PTB é o Partido Trabalhista Brasileiro. PDT é o Partido Democrático Brasileiro. A Unidade Popular utiliza a sigla UP. Fonte: https://www.tse.jus.br/partidos/partidos-politicos/registrados-no-tse Acesso: 13 abr. 2021.

2 A data do registro definitivo no Tribunal Superior Eleitoral (TSE) é 29 de março de 1990.

3 O registro oficial junto ao TSE data de 25 de agosto de 2005, com o nome Partido Municipalista Renovador (PMR). Posteriormente, passou a se chamar Partido Republicano Brasileiro. A denominação atual foi autorizada juridicamente em 2019.

4 Para mais informações sobre a proximidade entre o Republicanos e a Igreja Universal do Reino de Deus, sugerimos a leitura das seguintes reportagens: Partido ligado à Igreja Universal tenta vestir roupagem conservadora colando imagem ao Bolsonarismo (Revista Época, 18/09/2020, disponível em https://epoca. globo.com/brasil/partido-ligado-igreja-universal-tenta-vestir-roupagem-conservadora-colando-imagem-ao-bolsonarismo-24646335.Acesso: 15 abr. 2021. e O exército de obreiros da Universal na guerra santa por votos (Agência Pública, 17/11/2020, disponível em https://apublica.org/2020/11/o-exercito-de-obreiros-da-universal-na-guerra-santa-por-votos/. Acesso: 15 abr. 2021). 
por igrejas e demais associações que reúnam e defendam anseios tidos como adequados por parcela significativa dos fieis que frequentam tais instituições. E, para tanto, o ingresso na política eleitoral foi um fator determinante e uma maneira de ampliar a discussão pública em torno de pautas como religiosidade, direito à vida, sexualidade e composição familiar, entre outros.

De modo geral, é possível afirmar que nestas mais de três décadas pósredemocratização, a participação e a influência de partidos que se apresentam como ideologicamente ligados ao cristianismo, bem como de políticos que se identificam, eleitoralmente, como cristãos, aumentou bastante. Em parte, tal crescimento deve-se ao tripé "Política, Mídia e Filantropia", que foi idealizado pela Igreja Universal do Reino de Deus (IURD), conforme Maria das Dores Campos Machado (2001) e Ricardo Mariano (1999) apud Marcelo Camurça (2019, p. 128). Tal estratégia, é efetivada da seguinte forma:

[...] a hierarquia da igreja lança pastores como candidatos a posições políticas, que fazem suas campanhas eleitorais nos púlpitos e outros ambientes eclesiais, dirigidos para os membros das igrejas. Com essa fidelização de votos, os líderes religiosos, são eleitos como parlamentares. Depois, nesta condição de deputados vão atuar nas Comissões de Comunicação dos Parlamentos para obter concessões e rádios e TVs para suas igrejas. Paralelamente, com recursos dos fundos partidários estes parlamentares-religiosos criam entidades assistenciais, filantrópicas sob sua liderança pessoal, no modelo clientelista: distribuição de cestas básicas, fornecimento de orientação legal, clínicas médico-odontológicas, doação de contraceptivos à população pobre. Fechando o ciclo, através do uso destes meios de comunicação é feita a divulgação dessas lideranças político-religiosas e de suas ações caritativas. É um esquema em que cada um dos lados (política, mídia e filantropia) alimenta o outro e todos se complementam no reforço da presença das igrejas no cenário público-político (CAMURÇA, 2019, pg. 05).

\section{PARTIDO SOCIAL-CRISTÃO: CONSERVADOR É QUEM RESPEITA TRADICOOES, DIZ A SIGLA}

A história do PSC remonta ao ano de 1970, com a criação do então Partido Democrático Republicano. A denominação atual, adotada após a reabertura política de 1985, foi sugerida pelo político de Minas Gerais, Vítor Jorge Abdala Nósseis, naquela época, o principal dirigente da sigla. Conforme o portal da agremiação, a 
denominação "Social Cristão" vem da crença dos partidários de que o Cristianismo, mais que uma religião, é um estado de espírito que não segrega e não exclui, além de servir de base para que as pessoas tomem decisões de forma racional - daí, declara-se Pró-Vida e Pró-Família, abertamente contrário ao marxismo e historicamente anticomunista (PSC, 2020).

O estatuto partidário da sigla, disponível para download no portal da instituição, afirma no artigo 2., alínea I, que o partido "tem como fundamento a Doutrina Social Cristã, onde o Cristianismo, mais do que uma religião, representa um estado de espírito que não segrega, não exclui, nem discrimina, mas que aceita a todos [...]" (PSC, 2018, p. 01). Ainda conforme o regimento estatutário, a agremiação explicita no artigo 3. que o partido sempre agirá para

I - a defesa da vida desde a concepção; II - a defesa da família como base da sociedade; III - o respeito à dignidade da pessoa humana em primeiro lugar, procurando colocá-la acima de quaisquer valores, por mais importantes que eles sejam ou possam ser; [...] V - a realização e execução de seu programa com base na Doutrina Social Cristã; […] (PSC, 2018, p. 01).

Não há, porém, nenhuma espécie de detalhamento sobre o que vem a ser aquilo que o partido nomina como Doutrina Social Cristã. Em todo o restante do documento, o texto faz apenas menções a procedimentos administrativos, jurídicos, finanças, de filiação partidária e de funções a serem desempenhadas pelas comissões executivas da sigla, das quais fazem parte as lideranças do PSC. No site do partido, há um documento intitulado Manifesto Cristão Social, uma espécie de carta dos valores defendidos pelo PSC. Quem assina o texto, é o atual presidente nacional da legenda Everaldo Pereira. Logo em sua introdução, ficam evidentes mais algumas informações que norteiam o modo ideológico de fazer política para o partido. Vejamos:

O Social-Cristianismo surge no horizonte brasileiro através do Partido Social Cristão (PSC) com a finalidade de buscar solucionar ou amenizar as mazelas da humanidade, não só aproximando o homem de Deus, como também empunhando a sua própria bandeira, defendendo a vida desde a sua concepção, a família tradicional, a liberdade econômica, o estado mínimo, a preservação do meio ambiente, um pensado desenvolvimento sustentável, do bem-estar dos idosos e aposentados, dos níveis estáveis de emprego, visando sempre 
proporcionar à população mais saúde, conforto e dignidade, em suas etapas de vida (MANIFESTO SOCIAL CRISTÃO, s/d, p. 01, 2020).

No mesmo documento, o partido também se apresenta como situado à direita no espectro ideológico da política brasileira e atesta que sua concepção de conservadorismo passa pelo respeito às tradições sociais, o combate aos preconceitos de qualquer espécie, bem como outras formas de discriminação, além de ressaltar seu compromisso com aquilo que entende ser a ordem pública e a moralidade. O Manifesto Social-Cristão ainda apresenta outros entendimentos do PSC acerca, por exemplo, do direito à vida, à liberdade e à criatividade.

Ao governo compete proteger esses direitos cujo autor é o Criador [Deus]: O direito à vida é inviolável, sendo a base de todos os demais direitos humanos. Logo, o objetivo maior de toda política pública é a promoção de vida longa e saudável, com acesso ao conhecimento, a relações sociais plenas e a um padrão de consumo sustentável, resultando em uma existência humana digna a todo cidadão. [...] Defendemos o respeito à vida, valorização da família, garantia de propriedade privada, respeito à ordem e à autoridade constituída. Democracia e liberdade individual são instituições que devem ser preservadas por serem inerentes à dignidade e à identidade nacional (MANIFESTO SOCIAL CRISTÃO, s/d, pgs. 08-09, 2020).

Sobre a prática do conservadorismo, o partido revela que também o compreende como uma espécie de prática capaz de frear as violências constitucionais que, teoricamente, seriam praticadas pelas forças progressistas quando estas tentam destruir a paz e a prosperidade do país. O documento institucional do Partido Social Cristão frisa, ainda, que os membros da agremiação creem que o conservadorismo seja, antes de tudo, solidariedade social, uma vez que ao defender famílias promove, consequentemente, o combate aos males opositores que tentam desarticular este núcleo social.

REPUBLICANOS: PROXIMIDADES E AFASTAMENTOS COM A IGREJA UNIVERSAL DO REINO DE DEUS

Em sua página virtual, o partido se define como uma legenda de perfil político conservador, ancorada em valores cristãos, tendo a família tradicional como alicerce da sociedade e principal elemento social a ser preservado pela 
sociedade brasileira. No campo intitulado Visão, o portal da sigla afirma é um objetivo de curto prazo estabelecer um quadro partidário "mais alinhado aos conceitos da direita conservadora" (REPUBLICANOS, Visão, 2020). O presidente nacional do partido, deputado federal por São Paulo, Marcos Pereira, em texto publicado no site da legenda, tenta explicar o que o Republicanos entende por conservadorismo político: "O conservador clássico, ao contrário do que imaginam, não é um radical. É um agente moderador, defensor do equilíbrio, do bom senso, e tem sua conduta pública e privada bem distante dos extremos" (REPUBLICANOS, Manifesto e Programa, 2020).

Embora não seja ligado juridicamente à Igreja Universal do Reino de Deus (IURD), a quase totalidade de candidatos ou dirigente partidários do Republicanos possui proximidade com a denominação religiosa. Seu presidente, por exemplo, é bispo licenciado da igreja, segundo reportagem do site Congresso em Foco ${ }^{5}$. Isto proporciona uma prática relativamente corriqueira nos templos da denominação através da chamada "apresentação" dos candidatos aos fieis. É uma forma propagandear candidatos através do testemunho dado por outros líderes religiosos e até mesmo, por pedidos de votos realizados pelos próprios concorrentes.

Maia (2006, p. 103), garante que "dentre as igrejas evangélicas com maior atuação dentro do espaço político, estão a Igreja Universal do Reino de Deus (IURD), a Assembleia de Deus e a Igreja do Evangelho Quadrangular". Já o pesquisador Ari Oro, em seu texto A política da Igreja Universal e seus reflexos nos campos religioso e político brasileiros (2003), trata da geração de visibilidade política que a IURD fornece aos candidatos chancelados por sua liderança em todo o Brasil, principalmente, para aqueles que possuem influência e representatividade em nível estadual ou nacional.

Desde 1997 (a Igreja Universal do Reino de Deus) adotou, no âmbito nacional, o modelo corporativo da 'candidatura oficial', cujo número de candidatos para os distintos cargos eletivos depende do capital eleitoral de que dispõe. (...) Nas eleições (...) ao final dos cultos mais concorridos, sobretudo os dominicais, não somente era mencionado o nome e o número dos candidatos da igreja aos cargos eletivos, mas, algumas vezes, os próprios candidatos eram apresentados aos fiéis/eleitores ou, em caso de sua ausência, os bispos ou os pastores faziam subir no "palco/altar" alguns banners com fotos dos candidatos. No caso da Igreja

Para mais detalhes conferir a íntegra da reportagem intitulada Republicanos cresce nas eleições de 2020 e aumenta poder da Universal. Disponível em: https://congressoemfoco.uol.com.br/governo/bancada-membros-da-universal-em-2020/ Acesso: 15 de abr. 2021. 
Quadrangular há ainda a realização de reuniões prévias, semelhantes às realizadas pelos partidos políticos, para a indicação de seus candidatos. (ORO, 2003: 53-69).

$\mathrm{Na}$ mesma reportagem citada anteriormente, e veiculada pelo site Congresso em Foco, a IURD afirma que não participa institucionalmente de nenhuma disputa eleitoral e que também não possui controle sobre membros que queiram se candidatar a mandatos políticos, exceção de suas lideranças, das quais exige licenciamento das funções religiosas durante a campanha política. Não informa, porém, por quanto tempo se dá este afastamento.

O estatuto partidário do Republicanos, disponível para download no portal da agremiação, ainda carrega logotipo e marca do Partido Republicano Brasileiro, ou seja, o nome anterior da legenda. Há um informe com os dizeres da reunião partidária ocorrida em 7 de maio de 2019, na qual foi aprovado um novo estatuto, além da mudança para a identificação atual. Porém, como eles ainda não foram homologados pelo Tribunal Superior Eleitoral, não foram publicizados ${ }^{6}$.

A versão estatutária disponível para análise, traz logo em seu início um item denominado Programa. No texto pode-se ler que o partido "possui entendimento que a República, como comunidade de homens livres, deve ser o espaço de realização das aspirações de cada cidadão a uma vida digna, e ao pleno desenvolvimento de suas potencialidades materiais e espirituais" (REPUBLICANOS, Estatuto, p. 01, 2017). Mais adiante, em tópico chamado Religião, constam os seguintes dizeres: "O PRB [Republicanos] defende a liberdade de crença e a liberdade de culto. Ninguém deve ser preterido ou preferido em função de sua opção religiosa" (REPUBLICANOS, Estatuto, p. 03, 2017). São as duas menções no documento onde se lê algo próximo da esfera religiosa.

Embora haja uma proximidade pragmática entre a sigla e a organização religiosa, nem a IURD, como visto anteriormente, nem o Republicanos assumem tal relação. Pelo contrário: o partido também busca desfazer a imagem pública de uma organização vinculada à igreja ${ }^{7}$. Para tanto, busca reforçar discursos e posicionamentos institucionais à direita do espectro político e, sempre que possível, reforçar seu elo com presidente Jair Bolsonaro, assim

\footnotetext{
O estatuto disponível para consulta pública data de 26 de julho de 2017.

Embora o Republicanos tente se desvencilhar de vínculos oficiais com a Igreja Universal do Reino de Deus, na eleição de 2020, diversos candidatos do partido foram apoiados por membros da instituição, seja em atos de campanha explícita ou de modo não-oficial. Para mais detalhes, recomenda-se a leitura da reportagem $O$ exército de obreiros da Universal na guerra santa por votos, produzida pela agência Pública e disponível em https:/ /apublica.org/2020/11/o-exercito-de-obreiros-da-universal-na-guerra-santa-por-votos/ Acesso: 15 abr. 2021.
} 
como já havia feito com os ex-presidentes Luiz Inácio Lula da Silva, Dilma Rousseff e Michel Temer.

\section{ELEICÃO DE 2020: VOTACAOO EM MEIO AO CAOS PANDÊEMCO}

As disputas eleitorais municipais para cargos nas câmaras municipais Brasil afora, foram realizadas em 15 de novembro de 2020 por conta da pandemia gerada pela Covid-19. Houve um atraso proposital nas datas de votação, costumeiramente realizadas no primeiro domingo do mês de outubro, para tentar oferecer melhores condições de saúde pública às pessoas, durante o deslocamento até os respectivos locais de votação e durante todo o procedimento dentro dos colégios eleitorais.

Além disso, foi a primeira eleição disputada após o crescimento do movimento político chamado Bolsonarismo, caracterizado por conservadorismo político, retóricas que por vezes incitam a ruptura democrática e o acompanhamento ensandecido de posturas adotadas pelo presidente da República, Jair Bolsonaro (sem partido). Semelhantemente ao que já ocorrera em 2018, ainda havia um forte sentimento popular contrário aos partidos e candidatos que se apresentassem como situados à esquerda no espectro político. Em todo o país, foram preenchidos mais de 58 mil vagas legislativas municipais, segundo dados oficiais disponíveis no portal do TSE ${ }^{8}$.

\section{RELIGIÃO E POLITICA EM TERRAS PAULISTAS E PAULISTANAS}

Ao observarmos os números disponibilizados no site do TSE e referentes apenas ao estado de São Paulo, também podemos encontrar informações interessantes e que indicam espaços conquistados pelas siglas estudadas, os quais certamente serão usados para difundir posicionamentos ideológicos conservadores, visões políticas de direita e promover a defesa de interesses dos grupos sociais e instituições, com os quais tais partidos e os eleitos por eles compactuam. Somados, Republicanos e PSC lançaram 7.082 pessoas para as disputas legislativas realizadas em solo paulista, número equivalente a cerca de $10 \%$ do total de concorrentes por todas as agremiações?

\footnotetext{
8 O detalhamento desses números pode ser conferido na página do Tribunal Superior Eleitoral (TSE), e está disponível em https://www.tse.jus.br/eleicoes/estatisticas/estatisticas-eleitorais . Acesso: 15 abr. 2021.

9 Conforme o TSE, o estado de São Paulo registrou 83.944 pessoas aptas para concorrer às cadeiras legislativas dos seus municípios.
} 
O Republicanos teve 5.167 candidatos, dos quais 382 foram eleitos, ou seja, algo em torno de 7\%. Outras 3.520 pessoas ficaram na suplência, um percentual de 68\%. O Partido Social Cristão lançou 1.915 concorrentes. Teve 89 eleitos, ou 4\% do total, além de 57\% de suplência. Por outro lado, se considerarmos a quantidade de vereadores eleitos em todos os 610 municípios paulistas, por todas as siglas, o índice de assentos conquistados pelos partidos estudados neste trabalho muda. Vejamos: foram 6.945 vereadores eleitos em terras paulistas. Deste total, as pessoas filiadas ao Republicanos respondem por $7 \%$. Vereadores eleitos pelo PSC totalizam 4\% em média. Tais resultados indicam que embora tenham marcado presença em todo o estado, tais siglas ainda não ocupam lugares proeminentes em termos quantitativos nos legislativos paulistas, e ficam muito atrás em termos de representatividade, em relação a partidos mais tradicionais, melhor estruturados e com maior penetração no imaginário popular dos eleitores como MDB, PSDB, PT, Democratas e PTB.

Resultados eleitorais legislativos no estado de São Paulo - Eleição de 2020

\begin{tabular}{|c|c|c|c|c|c|}
\hline Partido & $\begin{array}{c}\text { Candidaturas } \\
\text { legislativas }\end{array}$ & Eleitos & $\begin{array}{c}\text { Taxa de } \\
\text { sucesso } \\
\text { eleitoral }\end{array}$ & Suplentes & $\begin{array}{c}\text { Taxa de suces- } \\
\text { so eleitoral }\end{array}$ \\
\hline Republicanos & 5.167 & 382 & 7 & 3.520 & 68 \\
\hline PSC & 1.915 & 89 & 4 & 1.092 & 57 \\
\hline
\end{tabular}

Em São Paulo, capital, os quatro partidos também apresentaram candidaturas à vereança. Num universo onde, todas as siglas somadas, foram registradas 1.886 pessoas aptas a concorrer, os dois partidos aqui estudados responderam por 155 delas, sendo 82 pelo Republicanos, e 73 pelo PSC. Eis os números: 4 pelo Republicanos, o equivalente a quase 5\% dos candidatos pela sigla, e 1 pelo PSC, ou 1\% daqueles que concorreram pela sigla. Curiosamente, as demais pessoas que disputaram o pleito paulistano por estes dois partidos, terminaram a disputa na condição de suplente. Mais uma vez, apesar dos resultados alcançados não serem extremamente significativo em termos quantitativos, ele aponta a existência de quase $10 \%$ de representantes populares no legislativo paulistano ${ }^{10}$, vinculados a partidos atrelados a defesa de pautas conservadoras

10 A Câmara de Vereadores de São Paulo conta com 55 representantes. 
e ligadas, umbilicalmente ou não, a denominações evangélicas, entre as quais se destaca a Igreja Universal do Reino de Deus. É perceptível, ainda, que a inserção destes indivíduos no universo camarário paulistano significa que grupos sociais ligados a eles, tentarão emplacar suas reivindicações no rol de matérias a serem analisadas e, quiçá, aprovadas em plenário.

Resultados eleitorais legislativos na cidade de São Paulo - Eleição de 2020

\begin{tabular}{|c|c|c|c|c|c|}
\hline Partido & $\begin{array}{c}\text { Candidaturas } \\
\text { legislativas }\end{array}$ & Eleitos & $\begin{array}{c}\text { Taxa de } \\
\text { sucesso } \\
\text { eleitoral }\end{array}$ & Suplentes & $\begin{array}{c}\text { Taxa de } \\
\text { sucesso } \\
\text { eleitoral }\end{array}$ \\
\hline Republicanos & 82 & 4 & 5 & 78 & 95 \\
\hline PSC & 73 & 1 & 1 & 72 & 98 \\
\hline
\end{tabular}

\section{CONSIDERACÕES FINAIS}

Por tudo aquilo que pudemos observar neste trabalho, sem dúvida, os quatro partidos estudados apresentaram resultados eleitorais díspares, o que evidencia em nossa opinião, duas linhas distintas entre eles. A primeira, formada por Republicanos e Partido Social Cristão, é caracterizada por siglas com estrutura partidária melhor arranjada e maior representatividade legislativa nos três níveis da federação. Por outro lado, Partido Trabalhista Cristão e Democracia Cristã, além de desempenho eleitoral pífio, também não contam com perspectivas de profissionalizar sua organização política, visto os péssimos resultados legislativos obtidos. Consequentemente, isto reforça a dificuldade delas em se fazer representadas nas câmaras municipais Brasil afora, especialmente, em grandes centros urbanos como São Paulo, onde existem maior profissionalização das agremiações.

Das cinco pessoas eleitas por esses partidos na eleição de 2020 para o legislativo paulistano, quatro são homens e apenas uma é mulher. Pelo PSC foi eleito Gilberto Nascimento Silva Júnior. Homem, branco, 41 anos e formado em Relações Internacionais, obteve 22.644 votos. Seu patrimônio declarado à Justiça Eleitoral é superior a R \$ 440 mil reais. Em perfil biográfico, publicado no site da Câmara dos Vereadores de São Paulo, afirma pertencer a

uma família pioneira de cristãos evangélicos na política: Gilberto Nascimento, seu pai, e Carlos Apolinário, seu tio, foram os primeiros a representar conservadores nas casas legislativas de SP e no Congresso Federal, em meados dos anos 1980. Na Câmara Municipal de São Paulo, apoia as pautas em defesa da 
vida e da família [...]. [É contrário] a criação de leis que apoiem de qualquer forma, o aborto, a ideologia de gênero nas escolas, a erotização de crianças, ou que sejam contra a liberdade religiosa ou a fé cristã, entre outras. [É] membro da bancada cristã (NASCIMENTO SILVA JÚNIOR, 2021).

Pelo Republicanos, o vitorioso mais votado foi André Luiz Santos Esteves com 41.584 votos. Em sua biografia define-se como "defensor de pautas da família e dos valores cristãos"11. É pastor licenciado da Igreja Universal do Reino de Deus, preto, casado, possui ensino superior completo e patrimônio declarado à Justiça Eleitoral no valor de R\$95 mil aproximadamente. É o líder da bancada do partido.

O segundo mais votado pelo Republicanos na eleição para câmara dos vereadores de São Paulo não disponibilizou sua declaração de bens ao TSE ${ }^{12}$. Trata-se de Sansão Pereira Filho, 60 anos, branco, casado e possuidor de diploma em nível superior. Obteve 39.709 votos. Afirma em sua biografia, disponível no site do legislativo paulistano que "com 29 anos tornou-se cristão, na Igreja Universal do Reino de Deus e há mais de 31 anos se dedica à Obra de Deus, e em trabalhos sociais" ${ }^{13}$.

O terceiro mais votado da bancada do Republicanos paulistano é o vereador Atílio Francisco da Silva, de 70 anos. Branco, casado e teólogo. Em sua declaração de patrimônio consta o valor de, aproximadamente, $\mathrm{R} \$$ 520 mil. Ex-presidente da Associação Beneficente Cristã, do ABC paulista, e pastor licenciado da Igreja Universal do Reino de Deus. A única mulher eleita pelo partido é Sonaira Fernandes de Santana, 31 anos, solteira, preta, advogada e possuidora de uma declaração de bens no valor aproximado de R\$ 95 mil, segundo o portal do TSE. Obteve 17.881. Eis alguns trechos de sua biografia, disponibilizada na página virtual da $\mathrm{CMSP}^{14}$ :

Cresceu sob os ensinamentos dos pais [...], sempre cultivando a fé e os valores da família e da comunidade. [...] Em 2014, Sonaira conquistou sua vaga de

\footnotetext{
11 Mais informações sobre o histórico do vereador podem ser obtidas no portal da Câmara de São Paulo, através do link https://www.saopaulo.sp.leg.br/vereador/andre-santos/. Acesso: 17 abr. 2021.

12 Para conferir, busque no link a seguir: https://divulgacandcontas.tse.jus.br/divulga/\#/candidato/2020/2030402020/71072/250000883826 Acesso: 17 abr. 2021.

13 Mais informações sobre o histórico do vereador podem ser obtidas no portal da Câmara de São Paulo, através do link https://www.saopaulo.sp.leg.br/vereador/sansao-pereira/. Acesso: 17 abr. 2021.

14 Mais informações sobre a vereadora podem ser obtidas no portal da Câmara de São Paulo, através do link https://www.saopaulo.sp.leg.br/vereador/sonaira-fernandes/. Acesso: 17 abr. 2021.
} 
estágio na PF e, por obra do destino ou designo divino, foi encaminhada para estagiar com o então escrivão Eduardo Nantes Bolsonaro. [...] Pouco depois, Sonaira foi convidada a participar do comitê de campanha de Eduardo Bolsonaro, que estava se candidatando pela primeira vez a deputado federal em 2014. Após a eleição, Sonaira Fernandes foi convidada a integrar a equipe do deputado federal [...].Sonaira morou em Brasília, onde também conheceu Jair Bolsonaro e sua equipe, sendo acolhida e vindo a participar de sua campanha presidencial em 2018 [...]. Em 2020 recebeu o convite de Eduardo Bolsonaro para disputar o cargo de vereadora na Câmara Municipal, sendo a vereadora da família Bolsonaro em São Paulo (FERNANDES DE SANTANA, 2021).

Por fim, acreditamos ser interessante ressaltar que a "bancada cristã-evangélica" eleita para a legislatura 2020-2024, conta ainda com outros dois parlamentares: Isac Félix (PL) e Rinaldi Digilio (PSL). Os seis parlamentares representam, quantitativamente, mais de $10 \%$ da vereança paulistana, composta por 55 representantes. E é inquestionável, embora não seja admitido oficialmente pela IURD, a ligação existente entre ela, enquanto instituição religiosa, e os vereadores que se apresentam como cristãos. Em nossa opinião, uma nítida constatação: a de que os interesses religiosos e conservadores passam, necessariamente, pela política, bem como aqueles pertencentes a outros grupos de interesses. A diferença é que, enquanto alguns assumem isto publicamente, como sindicatos, entidades ambientes ou associações que defendem grupos sociais minoritários, outros, como é o caso das igrejas, procuram distanciar-se disto.

\section{REFERENNCIAS}

CAMURÇA, Marcelo. Religião, política e espaço público no Brasil: perspectiva histórico/sociológica e a conjuntura das eleições presidenciais de 2018. Caderno de Estudos de Sociologia, Recife, 2019, vol. 2, n. 25.

FERNANDES DE SANTANA, Sonaira. Biografia. Disponível em: https://www.saopaulo.sp.leg.br/vereador/sonaira-fernandes/ Acesso: 17 abr. 2021.

MACHADO, Maria das Dores Campos. Além da Religião. Cadernos CERU: 2001, série 2, n.12, p. 139-150. MARIANO, Ricardo. Neopentecostais: sociologia do novo pentecostalismo no Brasil. São Paulo: Edições Loyola, 1999.

2011. Laicidade à brasileira: católicos, pentecostais e laicos em disputa na esfera pública. Civitas: Porto Alegre, v.11, n. 2, p. 238-258.

MOREIRA, Sonia Virgínia. Análise documental como método e técnica. In: DUARTE, Jorge e BARROS, Antonio. Métodos e técnicas de pesquisa em Comunicação. São Paulo: Atlas, 2005, pgs. 269-279. 
NASCIMENTO SILVA JÚNIOR, Gilberto. Biografia. Disponível em: https://www.saopaulo.sp.leg.br/ vereador/gilberto-nascimento/Acesso: 17 abr. 2021.

ORO, Ari. A politica da igreja universal e seus reflexos nos campos religioso e politico brasileiros. Revista Brasileira de Ciências Sociais, 2003, vol.18(53), pp.53-69.

PARTIDO SOCIAL CRISTÃO. Estatuto. Brasília/DF: 2018. Disponível em: https://psc.org.br/biblioteca/ . Acesso: 17 abr. 2021.

Manifesto Social Cristão. Brasília/DF: s/d. Disponível em: https://psc.org.br/biblioteca/ . Acesso: 17 abr. 2021. Site. Disponível em: https://psc.org.br/ . Acesso: 17 abr. 2021.

REPUBLICANOS. Estatuto. Brasília/DF: 2017. Disponível em: https://republicanos10.org.br/estatuto/. Acesso: 17 abr. 2021.

. Manifesto e Programa. Disponível em: https://republicanos10.org.br/manifesto-e-programa/. Acesso: 17 abr. 2021.

. Missão, visão e valores. Disponível em: https://republicanos10.org.br/missao-visao-valores/. Acesso: 17 abr. 2021.

Site. Disponível em: https://republicanos10.org.br/. Acesso: 17 abr. 2021.

STUMPF, Ida Regina. Pesquisa bibliográfica. In: DUARTE, Jorge e BARROS, Antonio. Métodos e técnicas de pesquisa em Comunicação. São Paulo: Atlas, 2005, pgs. 51-61.

TRIBUNAL SUPERIOR ELEITORAL. Site. Disponível em: https://www.tse.jus.br/ Acesso: 15 abr. 2021.

VALLE, Vinicius Saragiotto Magalhães. 2018. Direita religiosa e partidos políticos no Brasil: o caso do PRB e PSC. Teoria e Cultura, Juiz de Fora, v.13, n.2, p.85-100.

YAMAOKA, Eloi Juniti. O uso da internet. In: DUARTE, Jorge e BARROS, Antonio. Métodos e técnicas de pesquisa em Comunicação. São Paulo: Atlas, 2005, pgs. 146-163. 